\title{
REFLEXÃO BIOÉTICA SOBRE O ACESSO À SAÚDE SUPLEMENTAR NO BRASIL
}

\author{
Bruno Del Sarto Azevedo ${ }^{1}$, Chrisne Santana Biondo ${ }^{1}$, Edite Lago da Silva Sena ${ }^{2}$, Rita Narriman Silva \\ de Oliveira Boery², Sérgio Donha Yarid ${ }^{2}$
}

Resumo: Trata-se de uma revisão integrativa que objetiva desenvolver uma reflexão bioética a partir do que a literatura científica tem pesquisado sobre o acesso da população brasileira à saúde suplementar. Realizou-se uma busca na Biblioteca Virtual em Saúde, utilizando descritores, dos Descritores em Ciências da Saúde, relacionados à temática estudada, resultando na seleção de sete artigos. Evidenciou-se que o acesso aos serviços da saúde suplementar é conseguido apenas por grupos específicos de pessoas, o que representa um dado sintomático do mal-estar que vive a sociedade brasileira em razáo do sucateamento do setor público e da elitização dos serviços particulares. Fato este que conduz à consequente transgressão de princípios bioéticos como igualdade, justiça e equidade. Faz-se mister, então, a incorporação de reflexôes bioéticas nas discussões sobre o respeito à autonomia do indivíduo, com total direito de buscar o acesso a planos privados como meio de ver seus problemas de saúde resolvidos, e sobre a responsabilidade do Estado quanto à implementaçáo de um acesso à saúde equitativo e de qualidade aos cidadãos.

Palavras-chave: saúde suplementar, seguro saúde, acesso aos serviços de saúde, cobertura de serviços privados de saúde, bioética

\section{Reflexión bioética sobre el acceso a la salud complementaria en Brasil}

Resumen: Se trata de una revisión integradora, cuyo objetivo es desarrollar una reflexión bioética desde la literatura científica que investiga el acceso de la población a un seguro médico. Se realizó una búsqueda en la Biblioteca Virtual en Salud, utilizando los Descriptores de Ciencias de la Salud, respeto de la temática estudiada, lo que resultó en la selección de siete artículos. Se demostró que el acceso a los servicios de salud adicionales lo logran solo grupos específicos de personas, lo que evidencia el malestar de la sociedad brasileña debido al desguace del sector público y el elitismo de los servicios privados. Este hecho conlleva a consiguiente transgresión de los principios bioéticos, como la igualdad, la justicia y la equidad. Es imperativo incluir a la bioética en los debates acerca de la autonomía de la persona y su pleno derecho a solicitar acceso a los seguros de salud privados, como un medio de tener sus problemas de salud resueltos, y acerca de la responsabilidad del Estado en la implementación de un acceso equitativo a salud de calidad para los ciudadanos.

Palabras clave: salud complementaria, seguro salud, acceso a servicios de salud, amplitud de la salud privada, bioética

\section{Bioethical reflection regarding access to supplemental health in Brazil}

\begin{abstract}
It is an integrative review that aims to develop a bioethical reflection based on what the scientific literature has been researching about the Brazilian population's access to supplemental health. A search was conducted in the Virtual Health Library, using descriptors, from Health Sciences Descriptors, related to the studied theme, resulting in the selection of seven articles. It was evidenced that access to supplemental health services is fully achieved only by specific groups of people, which is symptomatic of a certain malaise that plagues the Brazilian society, due to the subpar conditions of the public sector and the elitism of the particular services. This fact leads to the consequent transgression of bioethical principles such as equality, justice and equity. As such, it becomes apparent that bioethical reflections on discussions about the respect for individual autonomy, with full right to seek access to private insurances as a means of seeing one's health problems solved, and on the responsibility of the State as the implementation of an equitable access to health care and quality service to citizens, must be incorporated.
\end{abstract}

Key words: supplemental health, insurance, health, health services accessibility, private health care coverage, bioethics

\footnotetext{
${ }^{1}$ Programa de Pós-Graduação em Enfermagem e Saúde da Universidade Estadual do Sudoeste da Bahia, Brasil Correspondência: brunodelsarto@outlook.com

${ }^{2}$ Programa de Pós-Graduação em Enfermagem e Saúde, Departamento de Saúde, da Universidade Estadual do Sudoeste da Bahia, Brasil
} 


\section{Introdução}

Antes da criação do Sistema Único de Saúde (SUS), existiam no Brasil as Caixas de Aposentadoria e Pensóes (CAPs), criadas no início do século XX. As CAPs eram fundos organizados por empresas, compostos por contribuição de trabalhadores, empregadores e consumidores dos serviços da empresa. Os beneficiários tinham direito à assistência médica, fornecimento de medicamentos, aposentadoria por idade, tempo de serviço ou invalidez e pensão para os dependentes em caso de morte(1). Este período histórico reflete uma sociedade na qual o direito à saúde do cidadão era primordialmente relacionado à posiçấo que ocupava no mercado de trabalho.

Passado um período de intensas transformaçóes e da promulgação da Constituição Federal de 1988, tem-se o atual sistema de saúde brasileiro, que se constitui em um mix público-privado, financiado principalmente por fundos privados. $\mathrm{O}$ sistema de saúde possui três setores: o setor público (SUS), em que os serviços são financiados e prestados pelo Estado; o setor privado (com ou sem fins lucrativos), com serviços financiados tanto por fundos públicos quanto privados; e o setor de seguros privados de saúde (saúde suplementar), com diferentes formas de planos de saúde, apólices de seguro e subsídios fiscais. Os componentes público e privado do sistema são distintos, mas interligados, e as pessoas podem utilizar os serviços em todos os três setores, de acordo com a facilidade de acesso ou a sua capacidade de pagamento(2).

Nessa perspectiva, o setor de saúde suplementar nasce com objetivos bastante claros: atender à necessidade dos meios de produção em manter o trabalhador em ação (medicina de grupo); contrabalançar a exploração da mão de obra médica pelas medicinas de grupo; e aproveitar um filão econômico emergente (grupos financeiros). Se no início as motivaçóes eram diversas, hoje todos querem explorar economicamente o mercado(3).

A regulamentação deste setor possui como marcos legais: a Lei no $9.656 / 98$, que dispóe sobre os planos e seguros privados de assistência à saúde(4); e a Lei no 9.961/00, que criou a Agência Nacional de Saúde Suplementar (ANS), como órgão do
Ministério da Saúde responsável pela sua regulação, normatização, controle e fiscalização(5).

Esse sistema misto resultou no panorama atual, em que $25,1 \%$ (6) da populaçáo brasileira têm, além do direito de acesso ao serviço público, a serviços de saúde providos por planos privados de saúde, uma vez que a rede pública tem dificuldades em atender, adequadamente, o restante da populaçáo que são dependentes exclusivamente do SUS(7).

Por esse motivo, algumas pessoas simplesmente substituíram os ideais de igualdade e equidade pelo direito à autonomia. Esta autonomia individual fundiu-se ao capitalismo de livre mercado para criar uma visão que torna os cuidados de saúde algo pelo qual cada pessoa deve pagar com seus próprios recursos(8). É importante, contudo, ter em mente o que estabelece a Carta Magna brasileira, quando afirma que "a saúde é direito de todos e dever do Estado" e, como tal, será garantida mediante, dentre outras coisas, o "acesso universal e igualitário às açóes e serviços para sua promoção, proteção e recuperação" (9).

Por sua vez, a ampliaçãa do conceito de bioética permitiu a incorporação ao seu escopo de diferentes situaçôes relacionadas à saúde pública, às políticas e ao sistema de saúde em vigor no Brasil. Isso inclui a universalidade das pessoas ao acesso a cuidados de saúde de qualidade $(10,11)$.

Diante do exposto, objetivou-se com esta pesquisa desenvolver uma reflexão bioética a partir de uma revisão integrativa acerca do que a literatura científica tem pesquisado sobre o acesso da população brasileira à saúde suplementar.

A relevância do estudo está em apresentar uma síntese do conhecimento produzido com relaçáo aos aspectos inerentes ao acesso à saúde suplementar no Brasil, promovendo atualização dos profissionais de saúde e da comunidade acadêmica, por meio de uma visão prévia do estado da arte do tema proposto, e fornecendo subsídios para novas pesquisas nesta área.

\section{Metodologia}

Trata-se de uma revisão integrativa da literatura, a qual tem por finalidade reunir e sintetizar re- 
sultados de pesquisas sobre um delimitado tema, de forma sistemática e ordenada, contribuindo para o entendimento aprofundado acerca do mesmo(12).

A investigação exploratória ocorreu em abril de 2013, por meio de pesquisa às bases de dados da Biblioteca Virtual em Saúde (BVS), Scopus e Web of Science. Os termos utilizados para a busca, selecionados a partir dos Descritores em Ciências da Saúde (DeCS), foram "Saúde Suplementar" e "Seguro Saúde", integrando cada um destes descritores com "Acesso aos Serviços de Saúde", "Cobertura de Serviços de Saúde", "Cobertura de Serviços Privados de Saúde" e "Cobertura Universal (Seguro Saúde)".

Estabeleceu-se como critérios de inclusão: artigo científico resultante de investigação, com disponibilidade de texto completo; ter como contexto a realidade do Brasil; e abordar a temática do acesso a serviços de saúde pela rede de saúde suplementar e/ou a cobertura dos brasileiros por planos privados de saúde.

A restrição efetuada à área geográfica justifica-se pela necessidade de traçar um perfil sobre a produção nacional de conhecimento acerca da temática pesquisada, uma vez que a importância dos planos e seguros de saúde é diferenciada a partir da sociedade em que estão inseridos.

Já os critérios de exclusão foram: artigos de reflexão, de atualização, textos para fóruns ou editoriais, debates, documentos oficiais de órgãos governamentais e qualquer artigo que não seja pesquisa original com delineamento metodológico bem definido.

Inicialmente foram encontrados 42 artigos completos disponíveis no banco de dados da BVS, 21 na Scopus e 1 na Web of Science. Em seguida, foi realizada leitura criteriosa dos títulos dos estudos encontrados, excluindo-se aqueles que apresentaram duplicidade entre as bases, selecionandose dez artigos. Estes, por sua vez, passaram por nova leitura dos títulos e dos resumos, bem como por leitura flutuante de todo o corpo do estudo, como forma de identificar quais deles, de fato, abordavam a temática pesquisada. Sendo assim, a amostra final foi de sete artigos que atendiam aos objetivos e critérios de inclusão e exclusão desta revisão.

Realizou-se, então, leitura completa do material, além da caracterização dos mesmos por meio de fichamento, de modo a compilar, dentre outras variáveis: título do artigo, identificação dos autores e do periódico, ano de publicação, objetivo e os principais resultados e conclusóes.

\section{Resultados e discussão}

Todos os estudos selecionados são artigos de pesquisa originais. Quanto ao ano de publicação, 2011 e 2008 contaram com dois artigos. Os demais anos, 2012, 2010 e 2004, tiveram um artigo publicado em cada. Este achado releva quão atual é a temática sobre planos e seguros privados de saúde, uma vez que os dispositivos legais que tratam sobre o assunto foram instituídos somente a partir de 1998.

Quanto à procedência da pesquisa, prevaleceram aquelas que investigaram a população da região Sudeste, em especial o estado de São Paulo. O interesse nesse tema é reflexo da maior taxa de cobertura por planos de saúde nessa regiáo, sendo os estados desta, juntamente com o Distrito Federal, os únicos com taxa maior que a média nacional. A região metropolitana da cidade São Paulo, por sua vez, abarca um total de $22 \%$ dos beneficiários de todo o país(6).

Nesse sentido, três estudos(13-15) assinalaram a ocorrência dessa concentração da população coberta por planos de saúde nos municípios do centro-sul do Brasil, que possuem uma melhor inserção socioeconômica, em detrimento dos municípios do interior das regióes Norte e Nordeste. Além desse dado por região, eles apontam ainda para o comportamento diferenciado apresentado pelas capitais, as quais possuem uma maior taxa de acesso aos planos, enquanto os maiores vazios de cobertura podem ser constatados nos municípios de menor porte. Esses eventos são corroborados por outros estudos $(2,6)$.

Além da concentração da cobertura, outro achado dos artigos revisados refere ao crescimento do setor de saúde suplementar no contexto brasileiro $(13,14)$. Fato este apoiado por outros estudos, 
que sinalizam para o crescimento tanto dos planos médico-hospitalares quanto dos planos exclusivamente odontológicos $(2,6,16,17)$.
Os principais pontos dos estudos selecionados para esta revisão podem ser visualizados no Quadro 1.

\begin{tabular}{|c|c|c|}
\hline Referência & Objetivos & Principais resultados e conclusóes \\
\hline $\begin{array}{l}\text { Machado AF, Andrade MV, } \\
\text { Maia AC. A relação entre } \\
\text { estrutura ocupacional e acesso } \\
\text { a plano de saúde no Brasil: } \\
\text { uma análise para } 1998 \text { e } 2003 \text {. } \\
\text { Cad. saúde pública. } 2012 ; \\
\text { 28(4): } 758-768 .(15)\end{array}$ & $\begin{array}{l}\text { Caracterizar a cobertura } \\
\text { de planos privados } \\
\text { de saúde segundo a } \\
\text { inserção dos indivíduos } \\
\text { no mercado de trabalho } \\
\text { brasileiro. }\end{array}$ & $\begin{array}{l}\text { Os trabalhadores ocupados e mais escolarizados são } \\
\text { os que possuem maior acesso a planos de saúde, o } \\
\text { que caracteriza os postos de trabalho desse perfil de } \\
\text { trabalhadores como de maior qualidade. Em resumo, } \\
\text { os achados revelam relação positiva entre cobertura de } \\
\text { plano, rendimento do trabalho e, em alguma medida, } \\
\text { sindicalizaçáo. }\end{array}$ \\
\hline $\begin{array}{l}\text { Malta DC, Moura EC, } \\
\text { Oliveira M, Santos FP. } \\
\text { Usuários de planos de saúde: } \\
\text { morbidade referida e uso } \\
\text { de exames preventivos, por } \\
\text { inquérito telefônico, Brasil, } \\
\text { 2008. Cad. saúde pública. } \\
\text { 2011; 27(1): 57-66.(14) }\end{array}$ & $\begin{array}{l}\text { Descrever as } \\
\text { características da } \\
\text { distribuição da } \\
\text { morbidade autorreferida } \\
\text { e acesso a exames } \\
\text { preventivos entre } \\
\text { usuários de planos de } \\
\text { saúde. }\end{array}$ & $\begin{array}{l}\text { Foram avaliadas } 54.353 \text { pessoas com } 18 \text { ou mais anos de } \\
\text { idade, sendo que } 41,8 \% \text { são beneficiários de planos de } \\
\text { saúde. A cobertura desses planos tende a aumentar com } \\
\text { a idade e com a escolaridade. Comparativamente aos não } \\
\text { beneficiários de planos de saúde, os homens beneficiários } \\
\text { apresentaram maior probabilidade de diagnóstico de } \\
\text { dislipidemia e as mulheres de realização de exames de } \\
\text { mamografia e de citologia oncótica e diagnóstico de } \\
\text { dislipidemia e osteoporose. }\end{array}$ \\
\hline $\begin{array}{l}\text { Cuginotti AP. Transição } \\
\text { tecnológica em uma operadora } \\
\text { de plano de saúde: o olhar do } \\
\text { usuário. Physis (Rio J.). } 2011 \text {; } \\
\text { 21(1): 159-176.(18) }\end{array}$ & $\begin{array}{l}\text { Caracterizar como os } \\
\text { usuários percebem } \\
\text { e se posicionam em } \\
\text { relaçáo à implantação } \\
\text { da Estratégia Saúde } \\
\text { da Família (ESF) por } \\
\text { uma operadora do tipo } \\
\text { autogestáo. }\end{array}$ & $\begin{array}{l}\text { Utilizando-se de grupos focais com usuários considerados } \\
\text { "aderidos" e "não aderidos" à ESF, a pesquisa revela que } \\
\text { os usuários têm uma compreensão bastante clara do } \\
\text { significado da estratégia, percebem as contradiçôes e } \\
\text { deficiências no processo de formulação e implantação } \\
\text { e mantêm um elevado grau de autonomia na escolha } \\
\text { dos serviços que lhe sejam mais adequados, muito } \\
\text { influenciados pelo tipo de inserção que têm no } \\
\text { estabelecimento bancário que mantém a operadora. } \\
\text { Percebem, ainda, o impasse da autogestáo entre manter } \\
\text { uma ampla rede credenciada de livre acesso ou conseguir } \\
\text { avançar no sentido de fazer da ESF o eixo estruturante de } \\
\text { sua rede assistencial. }\end{array}$ \\
\hline $\begin{array}{l}\text { Victora CG, Matijasevich } \\
\text { A, Silveira MF, Santos IS, } \\
\text { Barros AJD, Barros FC. } \\
\text { Socio-economic and ethnic } \\
\text { group inequities in antenatal } \\
\text { care quality in the public and } \\
\text { private sector in Brazil. Health } \\
\text { policy plan. 2010; } 25: 253- \\
\text { 261.(19) }\end{array}$ & $\begin{array}{l}\text { Investigar a qualidade } \\
\text { da assistência pré- } \\
\text { natal entre prestadores } \\
\text { públicos e privados. }\end{array}$ & $\begin{array}{l}\text { O número de consultas de pré-natal foi maior entre } \\
\text { as mulheres brancas e em melhor situaçáo financeira, } \\
\text { que também eram mais propensas a iniciar o pré-natal } \\
\text { no primeiro trimestre da gravidez. Os escores médios } \\
\text { de qualidade da assistência pré-natal foram de } 8,9 \text {, } \\
\text { entre as de melhor condição financeira, e de } 7,9 \text { entre } \\
\text { as mais pobres, de } 8,4 \text { em brancas e de } 8,1 \text { nas negras. } \\
\text { Essas diferenças parecem estar relacionadas a padrôes } \\
\text { de comparecimento e não de discriminaçáo. Os escores } \\
\text { médios de qualidade foram maiores no setor privado } \\
\text { (9.3) do que no setor público }(8.1) \text {. }\end{array}$ \\
\hline $\begin{array}{l}\text { Louvison MCP, Lebrão ML, } \\
\text { Duarte YAO, Santos JLF, } \\
\text { Malik AM, Almeida ES. } \\
\text { Desigualdades no uso e acesso } \\
\text { aos serviços de saúde entre } \\
\text { idosos do município de São } \\
\text { Paulo. Rev. saúde pública. } \\
\text { 2008; 42(4): } 733-740 .(20)\end{array}$ & $\begin{array}{l}\text { Analisar os fatores } \\
\text { relacionados à } \\
\text { determinaçáo e às } \\
\text { desigualdades no acesso e } \\
\text { uso dos serviços de saúde } \\
\text { por idosos. }\end{array}$ & $\begin{array}{l}\text { Observou-se associação entre a utilização de serviços } \\
\text { e sexo, presença de doenças, autopercepçáo de saúde, } \\
\text { interação da renda e escolaridade e posse de seguro } \\
\text { saúde. A análise isolada com escolaridade apresentou } \\
\text { efeito inverso. Foram observadas desigualdades no uso e } \\
\text { acesso aos serviços de saúde e inadequaçáo do modelo de } \\
\text { atençáo. }\end{array}$ \\
\hline
\end{tabular}




\begin{tabular}{|c|c|c|}
\hline $\begin{array}{l}\text { Blay SL, Fillenbaum GG, } \\
\text { Andreoli SB, Gastal FL. Equity } \\
\text { of Access to Outpatient Care } \\
\text { and Hospitalization Among } \\
\text { Older Community Residents } \\
\text { in Brazil. Med. care. 2008; } \\
\text { 46(9): 930-937.(21) }\end{array}$ & $\begin{array}{l}\text { Determinar se, conforme } \\
\text { exigido pela lei brasileira, } \\
\text { há acesso universal } \\
\text { e igualitário e uso } \\
\text { adequado dos serviços de } \\
\text { saúde pelos idosos. }\end{array}$ & $\begin{array}{l}\text { Possuir seguro de saúde privado facilitou o acesso } \\
\text { ambulatorial e a internaçáo hospitalar. A melhoria do } \\
\text { acesso é necessária para idosos sem seguros privados de } \\
\text { saúde, e para aqueles com pouca escolaridade. }\end{array}$ \\
\hline $\begin{array}{l}\text { Pinto LF, Soranz DR. Planos } \\
\text { privados de assistência à saúde: } \\
\text { cobertura populacional no } \\
\text { Brasil. Ciênc. saúde coletiva. } \\
\text { 2004; 9(1): 85-98.(13) }\end{array}$ & $\begin{array}{l}\text { Traçar o perfil da } \\
\text { cobertura dos serviços de } \\
\text { saúde suplementar. }\end{array}$ & $\begin{array}{l}\text { No sistema de saúde brasileiro os planos privados de } \\
\text { assistência à saúde configuram-se como mais um fator de } \\
\text { geração de desigualdades sociais no acesso e na utilizaçáo } \\
\text { de serviços de saúde, pois cobrem apenas uma parcela } \\
\text { especíica da população brasileira: pessoas de maior renda } \\
\text { familiar, de cor branca, com maior nível de escolaridade, } \\
\text { inseridas em determinados ramos de atividade do } \\
\text { mercado de trabalho, moradores das capitais/regióes } \\
\text { metropolitanas. }\end{array}$ \\
\hline
\end{tabular}

Quadro 1: Publicações científicas analisadas, segundo caracterização da referência, objetivos, principais resultados e conclusóes.

Apesar do acesso aos cuidados de saúde terem aumentado substancialmente após a criação do SUS, este ainda apresenta uma série de dificuldades em relação a seu efetivo funcionamento, o que faz com que uma grande parcela da população procure outras formas de atendimento. Dentre as dificuldades para o atendimento, estâo a desmarcação de consultas, as filas extensas, a longa espera para conseguir ser atendido e a falta de profissionais, que contribui para a demora da marcação de consulta(7).

Outro ponto importante a ser considerado na compreensão do sistema misto brasileiro é o predomínio da ideia, na populaçáo, de que o sistema privado é eficiente e o público não. Soma-se a isso uma sensação geral de insegurança que se aprofunda pelos problemas decorrentes de um modelo pouco eficiente, o que leva à constituição de argumentos para a escolha de assistência priva$\mathrm{da}(19-22)$.

Nessa perspectiva, evidencia-se a efetivação do princípio bioético da autonomia, uma vez que os usuários do SUS, na medida em que não se sentem adequadamente assistidos por este setor, têm o total direito de optar pela busca do acesso a seguros privados - e de ter esta decisão respeitada - como forma de ver seus problemas de saúde resolvidos.

Infelizmente, a maioria da população do país não pode optar por um sistema de melhor acesso e que lhe ofereça o atendimento de saúde adequado a suas necessidades. Em funçáo dessa maioria, emerge a bioética da proteção, que pode ser vista como uma ética da responsabilidade social do Estado, que deve assumir obrigaçóes perante as sociedades nas quais os cidadáos sofrem discriminaçóes, assimetrias e desigualdades gritantes(23). Não se trata, entáo, do sacrifício da liberdade pessoal em prol do interesse coletivo, mas sim de impulsionar práticas comprovadamente efetivas em prol do bem comum, restringindo-se apenas os aspectos da autonomia exercidos por aqueles que venham a interferir na implementação das açôes(24).

Um estudo realizado na perspectiva de caracterizar como os usuários de uma operadora de autogestão (OAG) percebem e se posicionam em relação à implantação da Estratégia Saúde da Família (ESF), encontrou como achado frequente a visão quase aristocrática que alguns deles têm de si mesmos e de seu modelo calcado na rede credenciada, em oposição à ESF(18). O autor destaca que eles consideram o modelo tradicional da operadora como "de primeira classe", enquanto a ESF representaria a "categoria econômica", com quem náo desejam ser comparados. Para esses usuários a ESF funcionaria como porta de entrada para o sistema, como no SUS, enquanto o modelo de rede credenciada garantiria o acesso e a livre escolha dos prestadores mais valorizados do mercado, conferindo status aos beneficiários da OAG. 
Neste sentido, percebeu-se a falta de reconhecimento da importância da ESF como modelo de assistência primária à saúde, capaz de garantir a continuidade do cuidado e se manter como eixo referencial do sistema. Não se reconhece também que mesmo os serviços e ações da atenção básica à saúde constituem gastos em saúde e necessitam de recursos econômicos para sua manutenção. Por esse motivo, a operadora precisa fazer com que os beneficiários apreendam a concepção de que a inserção de cuidados de nível secundário e terciário representa ao sistema de saúde um aumento considerável nos recursos necessários e, com isso, acarreta no aumento das desigualdades e redução da equidade.

Parece ser senso comum atrelar a condição financeira ao status de beneficiário de planos de saúde, uma vez que a variável que explica a existência e tamanho desse mercado é a renda familiar e individual. Logo, os que podem pagar optam por adquirir contratos dessas operadoras(17). E essa relação entre posse de seguros privados e o fator renda é amplamente demonstrada, em graus diferenciados, por seis $(13-15,19-21)$ dos sete estudos desta revisão.

Ao se falar no aumento da renda e do acesso aos planos de saúde, observa-se no Brasil um aumento do número de políticas socioeconômicas. Políticas como as açôes afirmativas que combatem a desigualdade estrutural de grupos mais vulneráveis à discriminação (25). Exemplo disso é a nova lei das cotas (Lei no 12.711/12), que estabelece que $50 \%$ das vagas das universidades federais sejam destinadas a estudantes de escolas públicas(26), o que significa, sob a perspectiva da bioética da proteção, a abertura de possibilidade à transformação social pelo empoderamento dos cidadãos constitutivos de grupos mais vulneráveis, pelo respeito às minorias, especialmente no que tange à prática da solidariedade e da justiça(27).

$\mathrm{O}$ acesso desses grupos às universidades resulta em aumento de seus anos de escolaridade e na formação de profissionais que poderão ter melhores vínculos empregatícios e melhor renda, o que permite o ingresso à saúde suplementar.

A revisão mostrou a relação diretamente proporcional entre renda e/ou escolaridade e acesso a plano de saúde $(13,14,20)$. Outro estudo(15) ao investigar a cobertura por planos de saúde, segundo a inserção dos indivíduos no mercado de trabalho brasileiro, aponta que trabalhadores ocupados e mais escolarizados são os que possuem maior acesso aos planos.

Outras variáveis, encontradas nos estudos, relacionadas ao grau de acesso à saúde suplementar referem-se ao gênero, etnia e idade. No que diz respeito ao primeiro, um estudo(13) encontrou predominância de mulheres. Por sua vez, no estudo que investigou o acesso e a relaçáo com a inserção no mercado de trabalho(15), foi encontrado um predomínio de mulheres entre o perfil de "inativos" e uma ligeira vantagem de homens no perfil de "ocupados". Na medida em que esta pesquisa mostrou que trabalhadores ocupados possuem maior acesso a plano de saúde, é possível inferir uma predominância do gênero masculino como população de maior cobertura.

Quanto à etnia, dois estudos $(13,19)$ apontaram uma maioria de pessoas de cor branca, comparadas a pardos e negros, entre aqueles com maior acesso à saúde suplementar. Para a variável idade, os resultados dos estudos indicaram uma predominância tanto de adultos (entre 20 e 49 anos) (13), como de idosos(14) entre os maiores cobertos pelos planos de saúde. Em um dos estudos, que investigou especificamente a população idosa(20), ficou demonstrada que a posse de seguro privado é maior entre aqueles idosos com idade inferior a 75 anos.

Um estudo assinalou a capacidade dos planos de saúde em abarcar uma populaçáo mais jovem, uma vez que essa se encontra em idade economicamente ativa e tem a possibilidade de estar empregada em uma empresa que ofereça diferentes tipos de contratação de planos, a partir da hierarquia profissional(2). Por outro lado, destaca-se que vem ocorrendo, de fato, um envelhecimento populacional mais intenso entre os beneficiários, principalmente em decorrência do aumento da importância das doenças crônico-degenerativas na populaçáo brasileira(28).

Nesse contexto, percebeu-se a transgressão de princípios éticos, no que tange a igualdade, a equidade e a justiça, à medida que pessoas de cer- 
tas etnias, bem como aquelas que ocupam determinados cargos ou que possuem melhores condiçôes financeiras têm acesso aos cuidados de saúde de alta tecnologia, enquanto outras que não estão incluídas nesses grupos não têm o acesso, sendo que, muitas vezes, trata-se de uma questão de vida ou morte. Por essa razão, a equidade requer que o cuidado essencial à saúde disponível a algumas pessoas numa sociedade seja também disponível a outras pessoas com necessidades semelhantes(8).

Os artigos trazem ainda dados que permitem avaliar a qualidade da assistência recebida pela populaçáo com acesso à saúde suplementar $(14,20)$. Os autores destacam que a avaliação do estado de saúde ruim foi menor entre os beneficiários de planos de saúde, quando comparados aos que dependem exclusivamente do SUS.

No que concerne à cobertura e frequência de procedimentos e/ou serviços, os resultados apresentaram diferenças. Uma pesquisa revelou que os planos privados não cobriam a totalidade de consultas médicas e que tinham baixa cobertura de próteses e de medicamentos(20). Outras mostraram que as pessoas com acesso a plano de saúde tinham frequências maiores de procedimentos, diagnóstico, exames, atendimentos em ambulatório e possibilidade de hospitalização em relação aos não beneficiários e/ou usuários do setor público $(14,19,21)$.

Assim, em decorrência da peculiar inserção do setor de saúde suplementar no Brasil, que oferece cobertura duplicada, são extremamente importantes as iniquidades observadas na oferta e utilização de serviços a favor da populaçáo com plano de saúde: este segmento disponibiliza uma oferta de serviços hospitalares e, principalmente, de equipamentos de alta complexidade muito superior à do $\operatorname{SUS}(2,29)$.

Em contrapartida, situaçóes como a figura da doença preexistente, bem como a carência e a lista de procedimentos como elementos reguladores do acesso aos serviços, passadas como mecanismos de justiça contratualista, funcionam, na verdade, como diques a impedir o acesso dos beneficiários aos cuidados de saúde necessários. Ainda assim, nesse aspecto o SUS e a saúde suplementar se assemelham, na medida em que ambos prome- tem, mas não cumprem. O primeiro por falta de recursos financeiros e uma gestão ineficaz; o segundo porque caso cumpra, verá seu objetivo de lucro prejudicado(3).

Com base no exposto, a saúde não pode seguir sendo vista como objeto vulgar de consumo acessível somente àquelas pessoas privilegiadas, de poder aquisitivo alto e capacidade para adquiri-la, como se fosse uma mercadoria qualquer(30). O acesso igualitário, justo e equitativo à saúde, visto como direito do cidadáo e dever do Estado, necessita ser provido de forma adequada, de modo que as pessoas possam desfrutá-lo com dignidade, principalmente aquelas mais frágeis e necessitadas.

\section{Consideraçóes finais}

Propôs-se, com este estudo, refletir, sob a perspectiva bioética, sobre o acesso a planos privados de saúde, a partir de revisão integrativa da literatura. Trata-se de um tema ainda pouco estudado, dada a contemporaneidade do assunto e dificuldade de obtenção de informaçóes.

Os artigos mostraram que as dificuldades na maior ou menor possibilidade de acesso ao SUS, atendimento inadequado nas urgências, longas filas no atendimento e demora na marcaçáo de exames, fazem com que uma grande parcela de pessoas procure uma alternativa para suprir suas necessidades de acesso aos serviços da saúde. Nesse contexto, a saúde suplementar mostra-se como solução a tais enfrentamentos vivenciados pelos usuários do sistema público, no que diz respeito à universalidade e equidade da assistência.

Com base na reuniáo e síntese dos estudos, foi possível evidenciar que a saúde suplementar configura-se como um fator gerador de iniquidades no acesso de serviços de saúde, uma vez que cobre somente determinados grupos populacionais no Brasil, que são os brancos, com maior renda individual e familiar, maior escolaridade, inseridos em determinados ramos do mercado de trabalho e moradores das capitais ou municípios de grande porte do centro-sul do país.

Desse modo, o acesso às ações e serviços de saúde apenas por grupos de pessoas específicas é um 
dado sintomático do mal-estar que vive a sociedade brasileira em razão do sucateamento do setor público e da elitização dos serviços particulares, o que leva à consequente transgressão de princípios bioéticos como igualdade, justiça e equidade.

Tal fenômeno pode mudar em virtude dos programas de açóes afirmativas que vêm sendo implementados, visando ao aumento do ingresso da população vulnerável às universidades, acrescendo possibilidades de uma carreira profissional, o que poderá implicar em um aumento na renda e maior adesão à saúde suplementar.

Assim, de acordo com o que versa a bioética da proteção, que norteia a concepção de uma maior abrangência das açôes de saúde, e partindo do pressuposto da equidade em saúde, que é um direito do cidadão que possibilita a igualdade no acesso à atenção à saúde, mediante necessidades semelhantes, os benefícios relacionados à renda e escolaridade deveriam estar associados à necessidade de saúde da população. Defende-se ainda o respeito à autonomia dos indivíduos sobre a escolha por um acesso diferenciado aos serviços de saúde, proporcionado pela saúde suplementar.
É imperativo que essa reflexão bioética passe a incorporar as discussóes que regem a organização e efetivação dos sistemas universais de saúde, no que concerne à responsabilidade do Estado sobre a implementação de um acesso equitativo e de qualidade aos cidadáos.

Não obstante a limitação do estudo, referente à quantidade reduzida de artigos encontrados que abordassem a temática, os mesmos mostraram-se suficientes e consistentes para alicerçar a reflexão bioética sobre a atual situação do acesso a planos privados de saúde e para apontar a necessidade de incremento na realização de estudos futuros sobre esse horizonte de incertezas que é o mercado de saúde suplementar.

Sugere-se, então, que novos estudos sejam realizados, investigando, principalmente, a população que mostra maior vulnerabilidade quanto à possibilidade de inserção no setor de saúde suplementar, verificando ainda os avanços e as lacunas existentes na abordagem bioética a essa temática, que se mostra relevante aos interesses coletivos e individuais.

\section{Referências}

1. Escorel S, Teixeira LA. História das políticas de saúde no Brasil de 1822 a 1963: do império ao desenvolvimento populista. In: Giovanella L, Escorel S, Lobato LVC, Noronha JC, Carvalho AI, organizadores. Políticas e sistema de saúde no Brasil. 1a reimp. Rio de Janeiro: Fiocruz; 2009: 333-384.

2. Paim J, Travassos C, Almeida C, Bahia L, Macinko J. The Brazilian health system: history, advances, and challenges. Lancet 2011; 377(9779): 1778-1797.

3. Andrade EM, Andrade EO. O SUS e o direito à saúde do brasileiro: leitura de seus princípios, com ênfase na universalidade da cobertura. Revista Bioética 2010; 18(1): 61-74.

4. Brasil. Lei no 9.656, de 3 de junho de 1998. Dispóe sobre os planos e seguros privados de assistência à saúde. Diário Oficial da União 4 jun 1998; Seçâo 1: 1.

5. Brasil. Lei $n^{\circ}$ 9.961, de 28 de janeiro de 2000. Cria a Agência Nacional de Saúde Suplementar - ANS e dá outras providências. Diário Oficial da União 29 jan 2000; Seção 1, Edição Extra: 5.

6. Ministério da Saúde (Brasil), Agência Nacional de Saúde Suplementar. Foco - saúde suplementar. 4a ed. Rio de Janeiro: ANS; 2012.

7. Santo CCE, Gonçalves TC, Oliveira DC, Gomes AMT. Memórias e representaçôes sociais do Sistema Único de Saúde por seus usuários. Escola Anna Nery Revista de Enfermagem 2012; 16(1): 96-102.

8. Drane J, Pessini L. Bioética, medicina e tecnologia: desafios éticos na fronteira do conhecimento humano. São Paulo: Centro Universitário São Camilo; Edições Loyola; 2005.

9. Brasil. Constituição (1988). Constituição da República Federativa do Brasil. Brasília: Senado Federal; 1988.

10. Organização das Nações Unidas para a Educação, a Ciência e a Cultura. Declaração Universal sobre Bioética e Direitos Humanos. Paris, 19 out. 2005. (acesso em 2013 Abr. 29). Disponível em: http://www.bioetica.catedraunesco.unb.br

11. Garrafa V. Bioética. In: Giovanella L, Escorel S, Lobato LVC, Noronha JC, Carvalho AI, organizadores. Politicas e sistema de saúde no Brasil. 1a reimp. Rio de Janeiro: Fiocruz; 2009: 853-869.

12. Mendes KDS, Silveira RCCP, Galvão CM. Revisão integrativa: método de pesquisa para a incorporação de evidências na saúde e na enfermagem. Texto \& Contexto Enfermagem 2008; 17(4): 758-764. 
13. Pinto LF, Soranz DR. Planos privados de assistência à saúde: cobertura populacional no Brasil. Ciência \& Saúde Coletiva 2004; 9(1): 85-98.

14. Malta DC, Moura EC, Oliveira M, Santos FP. Usuários de planos de saúde: morbidade referida e uso de exames preventivos, por inquérito telefônico, Brasil, 2008. Cadernos de Saúde Pública 2011; 27(1): 57-66.

15. Machado AF, Andrade MV, Maia AC. A relação entre estrutura ocupacional e acesso a plano de saúde no Brasil: uma análise para 1998 e 2003. Cadernos de Saúde Pública 2012; 28(4): 758-768.

16. Santos FP, Malta DC, Merhy EE. A regulação na saúde suplementar: uma análise dos principais resultados alcançados. Ciência \& Saúde Coletiva 2008; 13(5): 1463-1475.

17. Bahia, L. As contradiçóes entre o SUS universal e as transferências de recursos públicos para os planos e seguros privados de saúde. Ciência \& Saúde Coletiva 2008; 13(5): 1385-1397.

18. Cuginotti AP. Transição tecnológica em uma operadora de plano de saúde: o olhar do usuário. Physis 2011; 21(1): 159176.

19. Victora CG, Matijasevich A, Silveira MF, Santos IS, Barros AJD, Barros FC. Socio-economic and ethnic group inequities in antenatal care quality in the public and private sector in Brazil. Health Policy and Planning 2010; 25: 253-261.

20. Louvison MCP, Lebrão ML, Duarte YAO, Santos JLF, Malik AM, Almeida ES. Desigualdades no uso e acesso aos serviços de saúde entre idosos do município de São Paulo. Revista de Saúde Pública 2008; 42(4): 733-740.

21. Blay SL, Fillenbaum GG, Andreoli SB, Gastal FL. Equity of Access to Outpatient Care and Hospitalization Among Older Community Residents in Brazil. Medical Care 2008; 46(9): 930-937.

22. Cordeiro HA, Conill EM, Santos IS, Bressan AI. Por uma redução nas desigualdades em saúde no Brasil: qualidade e regulação num sistema com utilização combinada e desigual. In: Santos NR, Amarante PDC, organizadores. Gestão pública e relação público privado na saúde. Rio de Janeiro: Cebes; 2010: 129-151.

23. Boy R, Schramm FR. Bioética da proteção e tratamento de doenças genéticas raras no Brasil: o caso das doenças de depósito lisossomal. Cadernos de Saúde Pública 2009; 25(6): 1276-1284.

24. Kottow M. Bioética de proteção: consideraçôes sobre o contexto latino-americano. In: Schramm FR, Rego S, Braz M, Palácios M, organizadores. Bioética, riscos e proteçâo. 2a ed. Rio de Janeiro: UFRJ; Fiocruz; 2009: 29-44.

25. Vasconcelos SD, Silva EG. Acesso à universidade pública através de cotas: uma reflexão a partir da percepção dos alunos de um pré-vestibular inclusivo. Ensaio: Avaliação e Políticas Públicas em Educação 2005; 13(49): 453-468.

26. Brasil. Lei $\mathrm{n}^{\circ}$ 12.711, de 29 de agosto de 2012. Dispóe sobre o ingresso nas universidades federais e nas instituiçôes federais de ensino técnico de nivvel médio e dá outras providências. Diário Oficial da União 30 ago 2012; Seção 1: 1.

27. Braz M. Bioética, proteçâo e diversidade moral: quem protege quem e contra o quê na ausência de um referencial comum? In: Schramm FR, Rego S, Braz M, Palácios M, organizadores. Bioética, riscos e proteção. 2a ed. Rio de Janeiro: UFRJ; Fiocruz; 2009: 45-61.

28. Stivali M. Regulação da saúde suplementar e estrutura etária dos beneficiários. Ciência \& Saúde Coletiva 2011; 16(9): 3729-3739.

29. Santos IS, Ugá MAD, Porto SM. O mix público-privado no sistema de saúde brasileiro: financiamento, oferta e utilização de serviços de saúde. Ciência \& Saúde Coletiva 2008; 13(5): 1431-1440.

30. Garrafa V. Ampliação e politização do conceito internacional de bioética. Revista Bioética 2012; 20(1): 9-20.

Recebido: 23 de setembro de 2013

Aceito: 19 de novembro de 2013 